\title{
Hemopneumothorax in a COPD patient treated with noninvasive positive pressure ventilation: The risk of attendant anticoagulation
}

\author{
R Raghavan MDCM ${ }^{1}$, AK Ellis MD ${ }^{1}$, W Wobeser MD MSC FRCPC ${ }^{2}$, \\ KB Sutherland CD BSc(Pharm) MD FRCPC ${ }^{3}$, DE O'Donnell MD FRCPI FRCPC ${ }^{4}$
}

\begin{abstract}
R Raghavan, AK Ellis, W Wobeser, KB Sutherland, DE O'Donnell. Hemopneumothorax in a COPD patient treated with noninvasive positive pressure ventilation: The risk of attendant anticoagulation. Can Respir J 2004;11(2):159-162.

Noninvasive positive pressure ventilation (NIPPV) modalities have been proven to be effective in the setting of exacerbations of chronic obstructive pulmonary disease (COPD). Reported complications include pneumothorax, increased work of breathing, gastric distension and air embolism. This case demonstrates that patients with severe COPD on anticoagulant therapy are potentially at risk for the serious complication of combined lung barotrauma and hemorrhage while on acute NIPPV therapy. This is the first reported case of hemopneumothorax complicating NIPPV therapy.
\end{abstract}

Key Words: Complication; Hemopneumothorax; Hemothorax; Noninvasive positive pressure ventilation; Noninvasive ventilation

\section{Un hémopneumothorax chez un patient atteint de MPOC traité par ventilation en sur- pression non effractive : Le risque d'une anti- coagulation concomitante}

\begin{abstract}
Il est démontré que les modalités de ventilation en surpression non effractive (VSNE) sont efficaces pour calmer les exacerbations de la maladie pulmonaire obstructive chronique (MPOC). Les complications déclarées incluent un pneumothorax, un accroissement du travail ventilatoire, une distension gastrique et un aéroembolisme. Le présent cas démontre que les patients atteints de MPOC grave sous anticoagulothérapie sont potentiellement vulnérables à la grave complication de barotraumatisme pulmonaire combiné à une hémorragie pendant un traitement aigu de VSNE. C'est le premier cas déclaré d'hémopneumothorax compliquant un traitement de VSNE.
\end{abstract}

$\mathrm{T}$ he use of noninvasive positive pressure ventilation (NIPPV) in patients with acute exacerbations of chronic obstructive pulmonary disease (COPD) is common, and often either prevents or serves as a bridge to intubation and ventilation. The efficacy has been supported by clinical trials in the acute setting (1), but it is poorly tolerated in the chronic setting (2). Adverse effects directly related to NIPPV therapy are rare, although patients will commonly fail to respond, ultimately requiring intubation and mechanical ventilation. No patient characteristics have been identified to consistently predict who will respond successfully to NIPPV therapy (2), although nonresponders have been identified as those with more severe disease or those with factors contributing to increased mouth leaks (3).

The known adverse effects of NIPPV are rare but include increased work of breathing (4), barotrauma (5), ulcerations of the face from ill-fitting masks (6), limited access to airway secretions (6), gastric distension (6), aspiration (3), conjunctivitis (3) and air embolism (5). Hemothorax is an unreported complication of this therapy. We present the case of an 81-year-old man with severe bullous emphysema who developed a hemothorax while receiving NIPPV, likely facilitated by anticoagulation for his concomitant non- $Q$ wave myocardial infarction.

\section{CASE PRESENTATION}

An 81-year-old male ex-smoker had a past medical history of COPD on home oxygen therapy ( $3 \mathrm{~L} / \mathrm{min}$ via nasal prongs) and previous pneumonia complicated by a right-sided lung abscess three months before presentation, which was successfully treated without consequences. He had an episode of angina in the 1960s, but had had no further cardiac symptoms since that time. He had documented bullous emphysema and had been admitted to hospital several times in the past for exacerbations. His last measured forced expiratory volume in $1 \mathrm{~s}$ was $0.78 \mathrm{~L}$ ( $32 \%$ predicted). His medications at the time of admission were prednisone $5 \mathrm{mg}$ by mouth once daily, salbutamol $5 \mathrm{mg}$ via nebulizer as needed, ipratropium bromide $500 \mu \mathrm{g}$ via nebulizer as needed, furosemide $20 \mathrm{mg}$ by mouth once daily and omeprazole $20 \mathrm{mg}$ by mouth once daily.

He presented with a three-day history of gradually increasing shortness of breath at rest, with minimal change in his chronic sputum production. On the morning of presentation, he awoke from sleep at 02:00 with severe chest pain on his left side, associated with increased dyspnea. The pain was sharp and intense, lasting about $45 \mathrm{~min}$, with no radiation and no associated nausea, vomiting or diaphoresis. He administered a nebulizer of salbutamol and called for an ambulance.

\footnotetext{
${ }^{1}$ Department of Medicine; ${ }^{2}$ Division of Infectious Disease, Department of Medicine; ${ }^{3}$ Department of Diagnostic Radiology; ${ }^{4}$ Division of Respiratory and Critical Care Medicine, Department of Medicine, Queen's University, Kingston, Ontario

Correspondence: Dr W Wobeser, Division of Infectious Diseases, Department of Medicine, Room 3009, Etherington Hall, Queen's University, Kingston, Ontario K7L 3N6. Telephone 613-533-2978, fax 613-533-6304, e-mail wlw@post.queensu.ca
} 


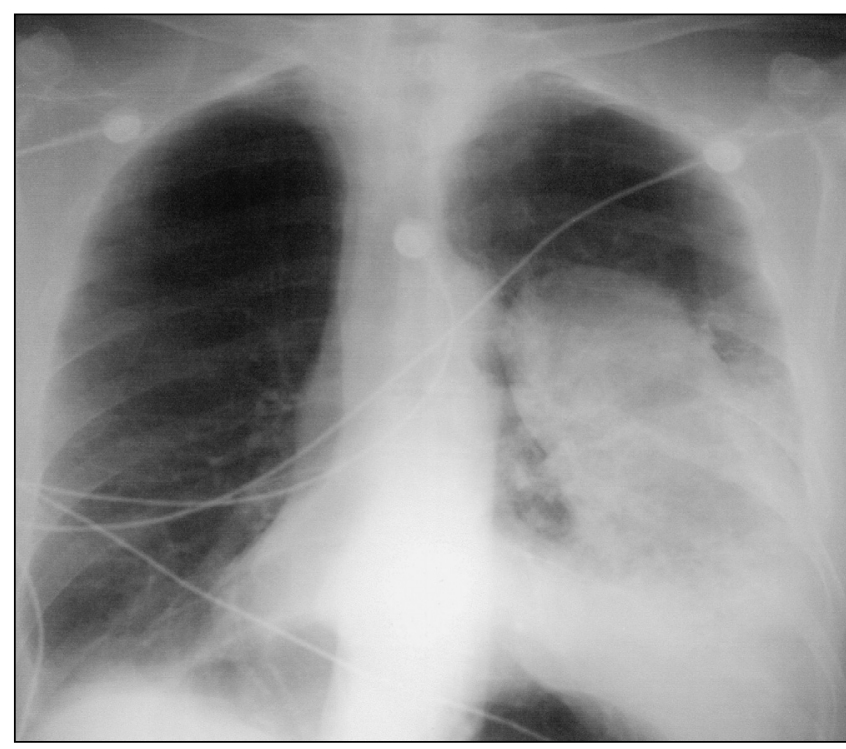

Figure 1) Portable chest $x$-ray demonstrating a new opacity overlying the left lower lobe with associated pleural fluid and air space opacities. There was an apparent collection of gas loculated medially

On arrival, he was pain free but still very dyspneic. His blood pressure was 111/61 $\mathrm{mmHg}$, heart rate was 108 beats/min and regular, temperature was $35.7^{\circ} \mathrm{C}$, oxygen saturation $\left(\mathrm{SaO}_{2}\right)$ was $90 \%$ on $4 \mathrm{~L}$ via nasal prongs (ambulance attendants recorded an $\mathrm{SaO}_{2}$ of $59 \%$ at home before administration of salbutamol nebulizers), and respiration rate was 32 breaths/min with indrawing and accessory muscle use. His chest examination revealed decreased breath sounds bilaterally with diffuse expiratory wheezes. His heart sounds were extremely faint, but there were no obvious murmurs or extra sounds. His abdomen was obese, but examination was unremarkable for any significant findings, and examination of his extremities revealed bilateral pitting edema to his knees.

The first arterial blood gas measurement, taken when the patient was on $4 \mathrm{~L}$ of oxygen by nasal prongs, revealed a $\mathrm{pH}$ of 7.25 , partial pressure of oxygen $\left(\mathrm{PO}_{2}\right)$ of $74.1 \mathrm{mmHg}$, partial pressure of carbon dioxide $\left(\mathrm{PCO}_{2}\right)$ of $76.4 \mathrm{mmHg}$ and bicarbonate concentration of $32.6 \mathrm{mmol} / \mathrm{L}$. Because of his severe respiratory distress and carbon dioxide retention, he was started on NIPPV (BiPAP ventilator, Respironics Inc, USA), with a setting of $10 / 5 \mathrm{~cm} \mathrm{H}_{2} \mathrm{O}$ and $30 \%$ oxygen. His white blood cell count was minimally elevated at $13.0 \times 10^{9} / \mathrm{L}$, his hemoglobin level was $136 \mathrm{~g} / \mathrm{L}$ and his platelet count was $408 \times 10^{9} / \mathrm{L}$. The patients electrolytes were normal, his creatinine concentration was $109 \mu \mathrm{mol} / \mathrm{L}$ and his urea concentration was $7.1 \mathrm{mmol} / \mathrm{L}$. His creatine kinase (CK) level was $134 \mathrm{U} / \mathrm{L}$. His first electrocardiogram (ECG) showed minimal ST depression in leads V4 to V6. A repeat ECG $3 \mathrm{~h}$ later showed resolution of these changes. A repeat arterial gas measurement $3 \mathrm{~h}$ later (BiPAP $10 / 5 \mathrm{~cm} \mathrm{H}_{2} \mathrm{O}, 30 \%$ oxygen) demonstrated a $\mathrm{pH}$ of $7.35, \mathrm{PO}_{2}$ of $68.7 \mathrm{mmHg}, \mathrm{PCO}_{2}$ of $58.9 \mathrm{mmHg}$ and bicarbonate concentration of $31.8 \mathrm{mmol} / \mathrm{L}$, and NIPPV was discontinued. A chest $\mathrm{x}$-ray demonstrated asymmetric prominence of the bronchovascular markings, in keeping with a COPD exacerbation. Additionally, there was suggestion of minimal lower right lung and pleural opacity, representing residual disease from prior pneumonia and an abscess. He was admitted to a stepdown unit with a diagnosis of an exacerbation of COPD and possible unstable angina, and he was treated with intravenous steroids, frequent bronchodilators and supplemental oxygen, aiming for a $\mathrm{SaO}_{2}$ of between $88 \%$ and $92 \%$. Serial CKs and ECGs followed. His second CK measurement was elevated at $297 \mathrm{U} / \mathrm{L}$, with a positive $\mathrm{MB}$ fraction of $32.7 \mathrm{ng} / \mathrm{mL}$ (mass index 11.0), and a troponin-I level of $5.030 \mu \mathrm{g} / \mathrm{L}$. An ECG at that time was unchanged. Thus, he was diagnosed with a non- $Q$ wave myocardial infarction and was started on enoxaparin $100 \mathrm{mg}$ subcutaneously every $12 \mathrm{~h}$ (the recommended dose for this patient by weight) and enteric-coated acetylsalicylic acid $81 \mathrm{mg}$ by mouth once daily. Because he was pain free at that point, no antianginal therapy was initiated.

The patient was clinically stable the following morning, but gradually became increasingly short of breath. He was restarted on NIPPV (settings $10 / 5 \mathrm{~cm} \mathrm{H}_{2} \mathrm{O}$ ) with minimal improvement. At approximately 14:00, he developed hemoptysis and worsening dyspnea. NIPPV was discontinued due to patient discomfort and ongoing mild hemoptysis. ECGs revealed no evidence of ischemia. Arterial blood gases were obtained on $100 \%$ fraction of inspired oxygen, which showed a $\mathrm{pH}$ of 7.44 , $\mathrm{PO}_{2}$ of $66 \mathrm{mmHg}, \mathrm{PCO}_{2}$ of $45.6 \mathrm{mmHg}$ and bicarbonate concentration of $30.6 \mathrm{mmol} / \mathrm{L}$. A chest examination revealed ongoing diffuse wheezing with decreased breath sounds, particularly on the left side. A portable chest $\mathrm{x}$-ray was obtained and demonstrated a new opacity overlying the left lower lobe, associated with pleural fluid, air space opacities and an apparent loculated gas collection (Figure 1). The differential diagnoses at that point included aspiration, rupture of a bulla and hydropneumothorax. Pulmonary embolism was considered, but felt to be unlikely because he was anticoagulated at the time. Given the patient's hemoptysis, enoxaparin was discontinued. Over the next two days, the patient continued to have hemoptysis and moderate respiratory distress, with no change on chest radiographs. A portable supine film suggested interval development of a cavity, confirmed also by a lateral study (Figure 2). The findings suggested an acute bronchopleural fistula within a complicated pleural space or a hydropneumothorax. A computed tomography scan of the chest (Figure 3) and a computed tomography-guided aspiration of the hydropneumothorax for diagnostic purposes were arranged. Approximately $15 \mathrm{~mL}$ of frank blood with clots was aspirated. No organisms were seen on Gram stain, and cultures were later proven to be negative. The patient's hemoptysis resolved, his respiratory status further improved, and no additional NIPPV was used. The most likely cause of hemothorax in this patient was positive pressure ventilation in the setting of anticoagulation.

\section{DISCUSSION}

NIPPV has been gaining increasing popularity as a noninvasive modality that can circumvent the need for endotracheal intubation. Several studies have demonstrated its effectiveness in a variety of clinical conditions, including in COPD patients with exacerbations of chronic respiratory failure (3). The risks that it carries in such a setting are only gradually becoming known.

A prospective study using NIPPV in patients with COPD demonstrated improvements in oxygenation, a decreased rate of intubation, a decreased length of stay in the intensive care 


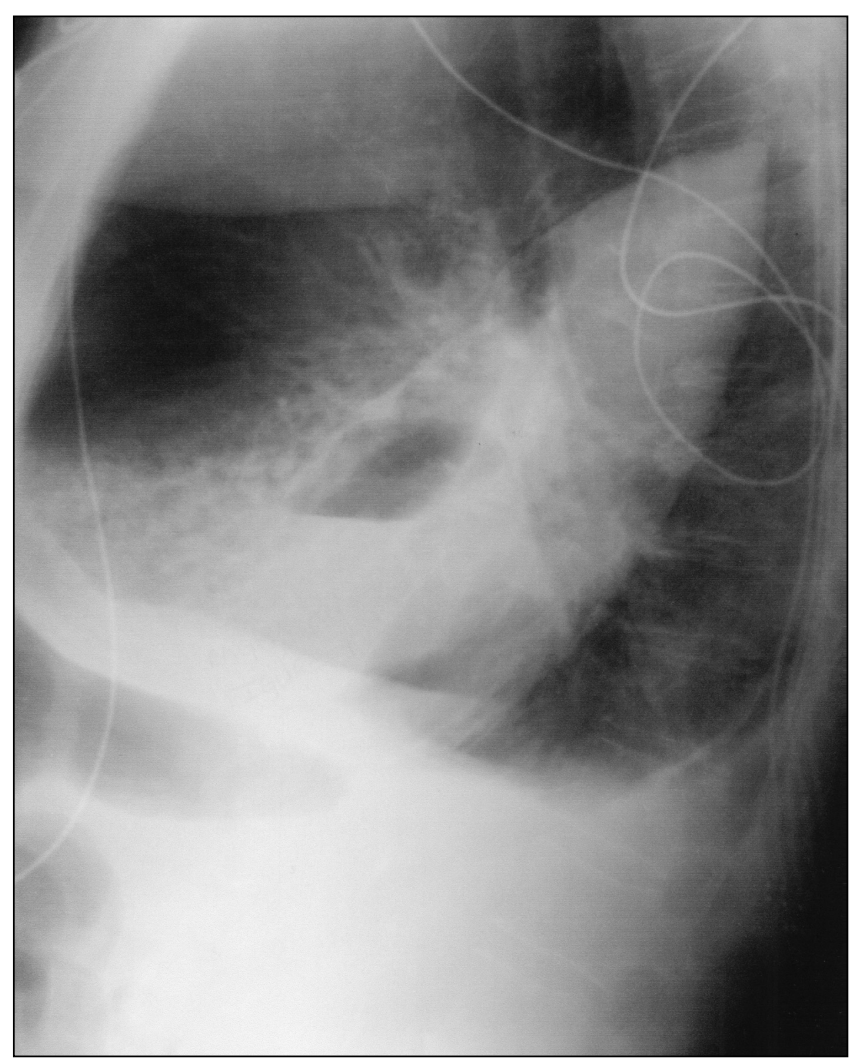

Figure 2) Lateral radiograph demonstrating a complex left hydropneumothorax with a large fluid collection within the fissure, accounting for the unusual appearance in Figure 1, and an air fluid level most likely accounting for the appearance of a cavity on the follow-up supine study. There was air space disease within the lingula, possibly representing hemorrhage

unit, decreased hospitalizations and decreased mortality at the end of one year (7). No specific patient or disease characteristics (such as the presence of bullae or the attendant use of anticoagulants) that influence the outcome of NIPPV therapy have been identified.

The clinical setting of concomitant unstable angina and COPD exacerbations is not uncommon. The combined use of anticoagulants with NIPPV appears, in the present case, to be attached to further risks. Antithrombotic therapy with enoxaparin and aspirin has been found to be effective in unstable angina, with a documented increase in minor but not major bleeding (8). It is known, however, that iatrogenic coagulopathy is one of the most common causes of nontraumatic hemothoraxes (9). A review of 14 cases revealed that during anticoagulation therapy for acute pulmonary embolus with pulmonary infarction, most hemothoraxes occurred within one week (9). All cases described were pure hemothoraxes with no complicating pneumothoraxes.

The presence of a pneumothorax in addition to a hemothorax, as in the present case, invokes an additional mechanism of injury. Pneumothorax, as a complication of NIPPV use, has been documented. Most cases describe overnight NIPPV use in patients with chronic COPD. In fact, COPD itself (particularly with the presence of bullae) predisposes patients to spontaneous pneumothoraxes. A review by Sahn and Heffner (10) stated that subpleural bullae are found during video-assisted thorascopic surgery in $76 \%$ to $100 \%$ of patients

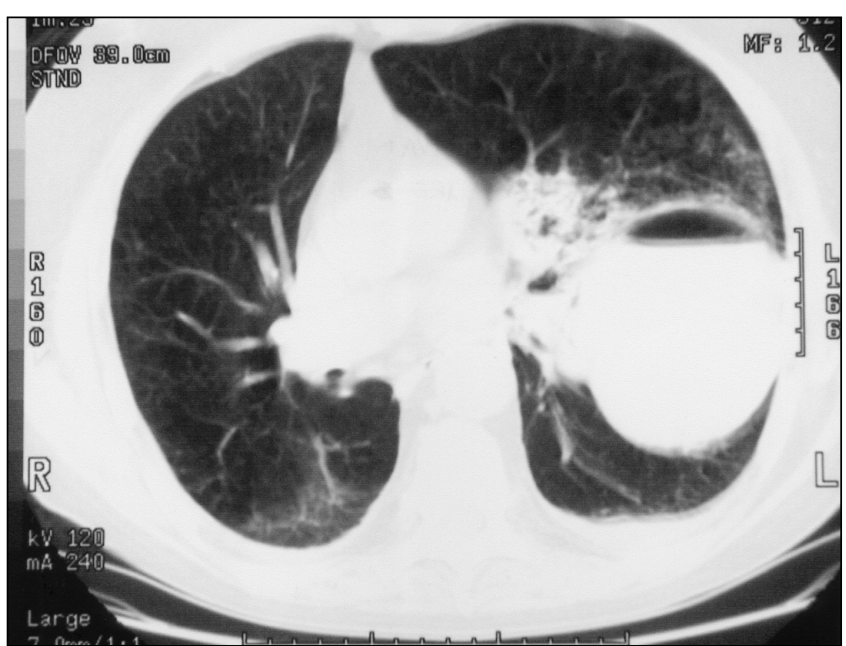

Figure 3) Lung window focused on the findings in the left hemithorax demonstrating the simple air fluid level within the left fissure and the air space disease in the lingual. The fluid collection has a high attenuation, similar to the blood within the left ventricle, suggesting a hemothorax (approximate size $14 \mathrm{~cm} \times 10 \mathrm{~cm} \times 9 \mathrm{~cm}$ )

who have suffered a pneumothorax (10). The proposed mechanism is gas trapping caused by the emphysematous condition, leading to increased pressures and subsequent rupture of alveoli. By increasing positive end-expiratory pressure (PEEP) via NIPPV, pressures within the alveoli are higher, further increasing the risk for barotrauma. To minimize this risk, it is currently recommended that applied PEEP should not exceed automatic PEEP.

Hemopneumothorax, although rare, is the most common cause of spontaneous hemothorax (10). With the advent of thoracotomy as a therapeutic manoeuvre, the mechanism of injury was discovered to be rupture of adhesions in the parietal pleura after a spontaneous pneumothorax.

Thus, the likely mechanism in the present case was a bronchopleural fistula and blood vessel rupture secondary to NIPPV use leading to intrathoracic hemorrhage in the presence of concomitant anticoagulation. The acuteness of the presentation with radiological evidence of a hydropneumothorax, as well as the temporal association of the hemoptysis with the use of NIPPV and low molecular weight heparin, make NIPPVinduced hemothorax the most likely cause. No other cases of NIPPV-induced hemothorax have been described thus far in the literature. However, with the increasing popularity of NIPPV use and the frequency with which unstable angina or non- $Q$ wave myocardial infarction occur concomitantly with COPD exacerbations, this complication may occur more frequently in the future. Particularly at risk are patients with a known history of severe COPD and/or radiological evidence of bullae. Clinicians should therefore be aware of the risks that different patient characteristics present and tailor their use of ventilatory support accordingly. In particular, careful titration of NIPPV with lower PEEP settings and monitoring of anticoagulation would help to prevent major complications.

No independent funding was provided for the preparation of this manuscript. 


\section{REFERENCES}

1. Poponick JM, Renston JP, Bennett RP, Emerman CL. Use of a ventilatory support system (BiPAP) for acute respiratory failure in the emergency department. Chest 1999;116:166-71.

2. Criner GJ, Brennan K, Travaline JM, Kreimer D. Efficacy and compliance with noninvasive positive pressure ventilation in patients with chronic respiratory failure. Chest 1999;116:667-75.

3. Miletin MS, Detsky AS, Lapinsky SE, Mehta S. Current topics: Non-invasive ventilation in acute hypoxemic respiratory failure. Intensive Care Med 2000;26:242-5.

4. Katz-Paptheophilou E, Heindl W, Gelbmann H, Hollaus P, Neumann M. Effects of biphasic positive airway pressure in patients with chronic obstructive pulmonary disease. Eur Respir J 2000;15:498-504.

5. Hung SC, Hsu HC, Chang SC. Cerebral air embolism complicating bilevel positive airway pressure therapy. Eur Respir J 1998;12:235-7.
6. Poponick JM, Renston JP, Emerman CL. Successful use of nasal $\mathrm{BiPAP}$ in three patients previously requiring intubation and mechanical ventilation. J Emerg Med 1997;15:785-8.

7. Martin TJ, Sanders MH, Bierman MI, Hovis JD. Noninvasive application of bi-level positive airway pressure to prevent endotracheal intubation in acute respiratory failure. Crit Care Med 1994;23:A129. (Abst)

8. Cohen M, Demers C, Gurfinkel EP, et al. A comparison of low-molecular weight heparin with unfractionated heparin for unstable coronary artery disease. N Engl J Med $1997 ; 337: 447-52$

9. Martinez FJ, Villanueva AG, Pickering R, Becker FS, Smith DR. Spontaneous hemothorax. Medicine 1992;71:354-66.

10. Sahn SA, Heffner JE. Spontaneous pneumothorax. N Engl J Med 2000;342:868-74 


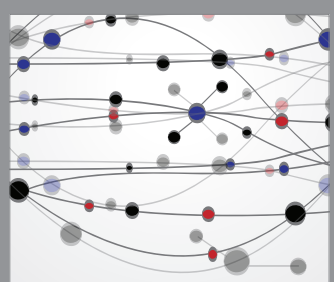

The Scientific World Journal
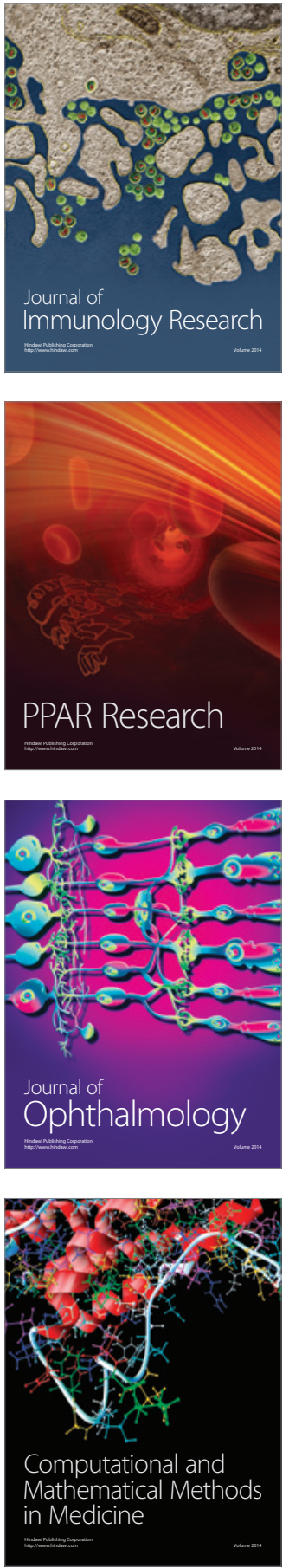

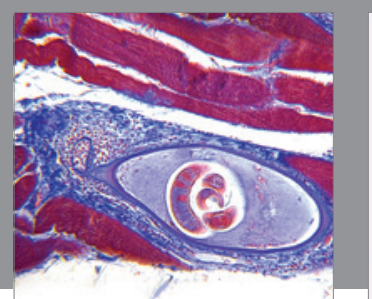

Gastroenterology Research and Practice

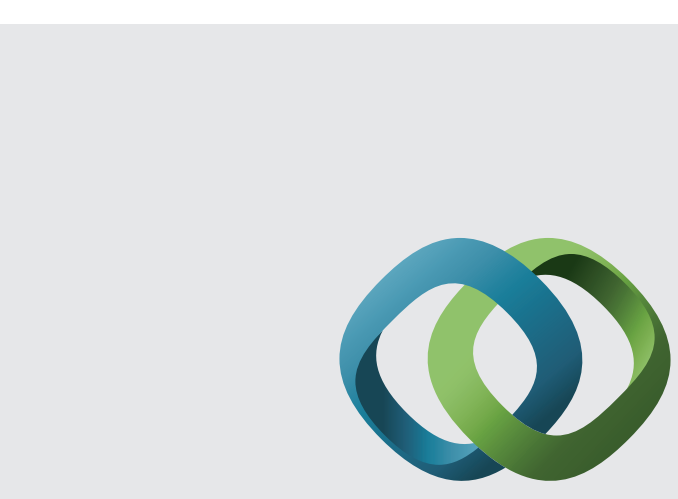

\section{Hindawi}

Submit your manuscripts at

http://www.hindawi.com
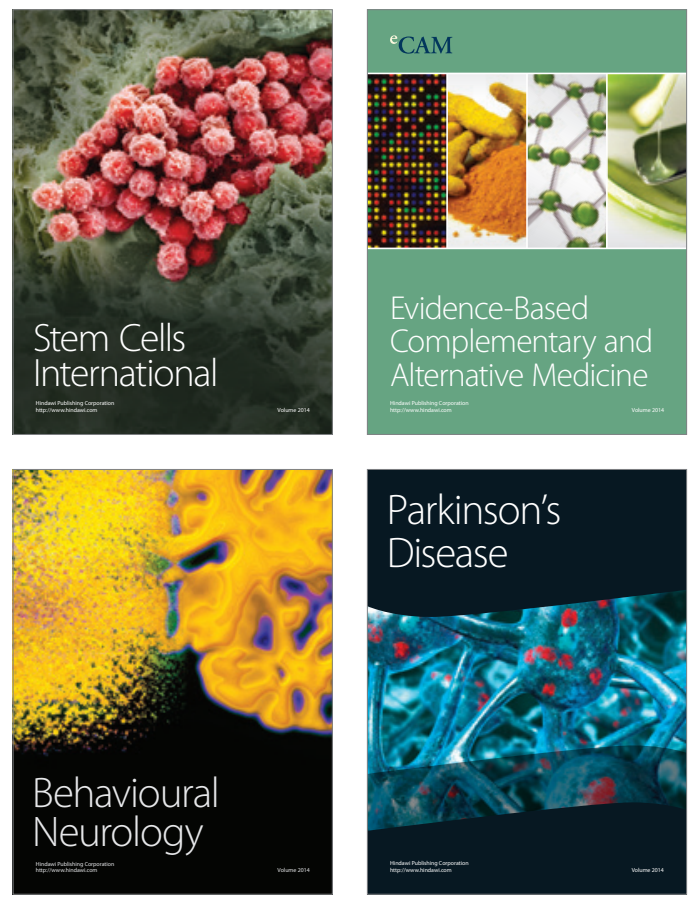
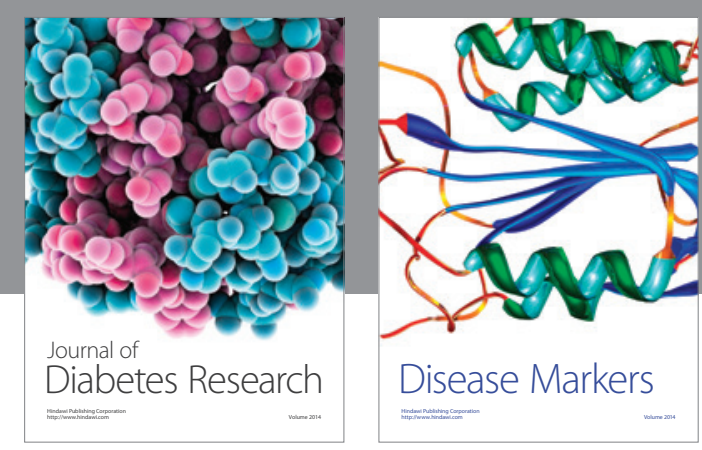

Disease Markers
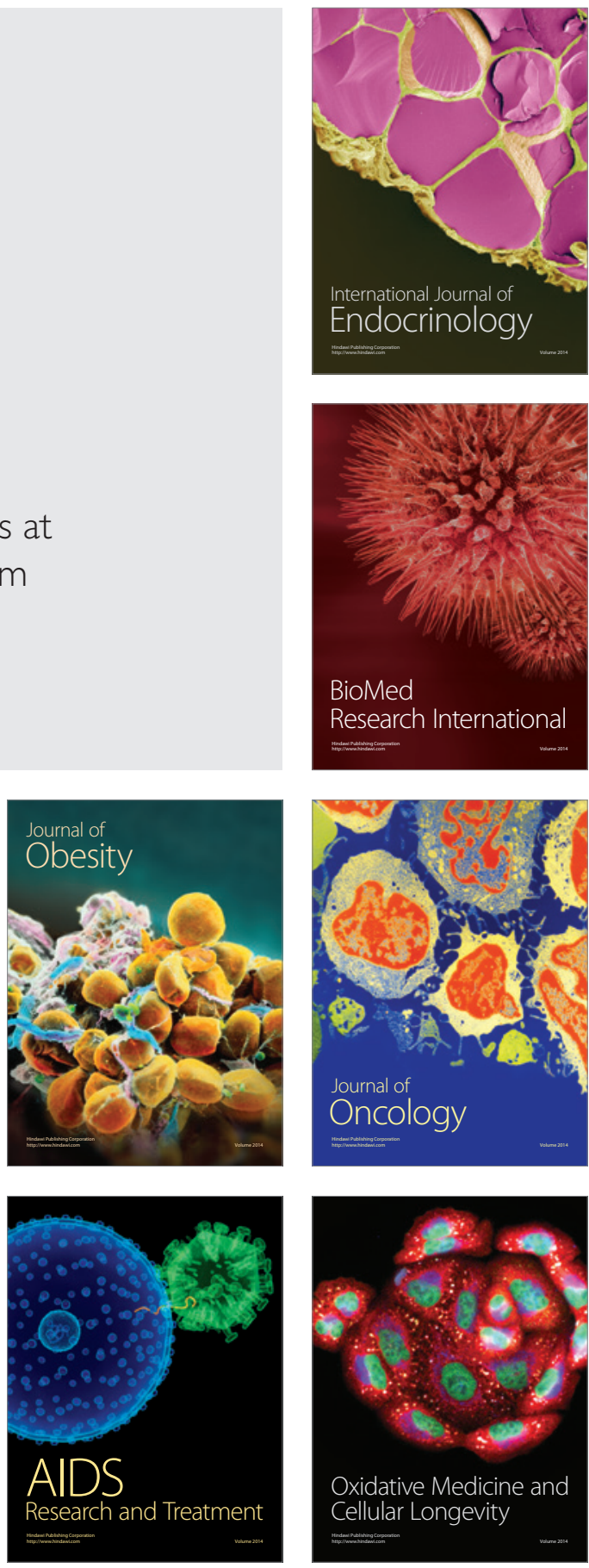